\title{
Sobre 'El factor Rosas'. Comentario de Roy Hora a Juan Manuel de Rosas. La construcción de un liderazgo político de Raúl O. Fradkin y Jorge Gelman
}

\author{
About "the Rosas factor". Commentary by Roy Hora on Juan Manuel de \\ Rosas. La construcción de un liderazgo político by Raúl O. Fradkin and Jorge \\ Gelman
}

RAÚL FRADKIN Y JORGE GELMAN

\section{Resumen}

Se examinan las principales observaciones críticas realizadas por Roy Hora a nuestro libro sobre Rosas y se explicitan y argumentan los fundamentos del enfoque adoptado, así como los alcances y límites de la contribución.

\begin{abstract}
We analyze the main critical observations made by Roy Hora on our Rosas book, and we argue and explain the grounds of our approach as well as the scope and limitations of the contribution.
\end{abstract}

Palabras clave: factor Rosas - Roy Hora biografía - historia
Keywords: the Rosas factor - Roy Hora biography - history

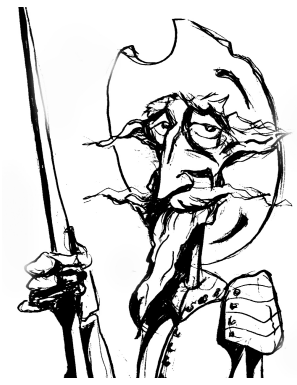

Recibido con pedido de publicación el 5 de octubre de 2016 Aceptado para su publicación el 30 de octubre de 2016 Versión definitiva recibida el 15 de noviembre de 2016

Raúl Fradkin, Universidad Nacional de Luján, Universidad de Buenos Aires, Argentina; e-mail: raul.fradkin@gmail.com

Jorge Gelman, Universidad de Buenos Aires, Instituto Ravignani - Consejo Nacional de Investigaciones Científicas y Técnicas, Argentina; e-mail: jorgegelman@gmail.com 
“El mar es un azar ¡Qué tentación echar una botella al mar!” decía Mario Benedetti en uno de sus versos entrañables. De alguna manera, publicar un libro se asemeja a echar una botella al mar y resignarse y admitir que una vez que ha sido lanzado no habrá modo de controlar ni sus usos ni sus lecturas. De poco y nada valdrán las aclaraciones, las disculpas o proclamar intenciones y motivaciones y, a lo sumo, a este fin van dedicadas unas pocas líneas como introducción. Difícilmente sean suficientes y lo más probable es que el lector les preste superficial atención o sencillamente decida más o menos voluntariamente dejarla de lado.

Como autores y como habituales lectores todos lo sabemos. Individuo libre por excelencia, el lector -y sobre todo el crítico- debe ser a su modo algo arbitrario y desalmado y es una suerte que así sea porque solo de ese modo se hace posible que su lectura sea crítica, aguda y enriquecedora. Y más cuando el universo posible de lectores de una biografía sobre Juan Manuel de Rosas constituye un verdadero océano, vasto hasta la inmensidad que pueda imaginarse y por demás proceloso. Lo sabíamos cuando empezamos su escritura y por eso dudamos de emprenderla: no habría en ese universo demasiados que pudieran quedar completamente satisfechos porque aunque sea exagerado decirlo así, hay tantos Rosas como lectores sobre Rosas. Una biografía sobre una figura que ocupa un espacio tan controvertido como desmesurado en la historia rioplatense y que ha forjado e informado en torno a ella los más variados pliegues de los imaginarios que la sociedad argentina tiene de ella misma y de su historia, no podía ser satisfactoria. Menos podía ser definitiva y no solo porque no hay ninguna historia o biografía que pueda tomarse como definitiva salvo que uno esté decidido a clausurar el mismo objeto y función de la historiografía.

Pero además vale la pena advertir desde el inicio que si la aspiración lógica y deseable del lector crítico es la libertad más absoluta para leer un texto, sin embargo dicha libertad suele ser más una aspiración que un resultado logrado. El contexto en el que se lee y las experiencias pasadas condicionan tanto a ese lector como al que investiga y escribe. Así resulta seguramente inevitable que nuestra escritura de este Rosas haya estado influida por nuestra experiencia de vida y de trabajo académico de las últimas décadas de la historia argentina, como también la de nuestro lector. Ya volveremos sobre ello. Lamentamos decirlo, porque aspiramos a la libertad, pero esta siempre es bastante limitada, para unos y para otros... Y claro también para nuestros biografiados. Podemos querer cambiar al mundo de cierta manera, pero las paredes con las que chocamos pueden ser muy duras.

Por decisión y por convicción, entonces, optamos por escribir una biografía que Roy Hora ha calificado como "peculiar" y su lectura propone una posible clave interpretativa de esa peculiaridad: "desde el punto de vista analítico, el trabajo de Fradkin y Gelman opta por no colocar en el centro de sus 
preocupaciones a Rosas en tanto actor político". Digámoslo sin vueltas: Roy acierta al subrayar que no nos propusimos y menos escribimos una biografía de Rosas, de acuerdo al modo en que habitualmente se entiende que debe ser escrita una biografía pero no estamos de acuerdo, en cambio, en que no hayamos situado a Rosas como actor político en el centro de nuestras preocupaciones.

Nuestra escritura no buscó basarse en el hallazgo de documentación que hasta ahora no se hubiera conocido o no haya sido consultada. Su soporte novedoso, si alguno tiene, estaba en otro lugar, en el vasto y notablemente enriquecido conocimiento acumulado en las últimas décadas por la historiografía sobre Rosas y sobre la sociedad de la que emergió y a la que gobernó Rosas y a la que sin duda ayudó a transformar en diversos sentidos que esa literatura nos ayudó a comprender. En este sentido, lo decimos en el libro pero vale la pena aquí reiterarlo, nuestra biografía de Rosas es muy poco y muy parcialmente nuestra. Nadie debe, por cierto, sentirse comprometido involuntariamente por el uso que hemos hecho de sus contribuciones.

El énfasis que hemos puesto en examinar las coyunturas y los mudables contextos en que Rosas tuvo que tomar decisiones transcendentes -sea para su vida como para su liderazgo o su gobierno- parecen llevarlo a Roy Hora a considerar que desde el punto de vista analítico nuestro enfoque no termina siendo demasiado diferente del que, por ejemplo, había adoptado John Lynch: así postula que "el enfoque es similar: Rosas es situado en su contexto histórico, $\mathrm{y}$ es este nivel de análisis el que le otorga inteligibilidad y norte al relato biográfico" y más adelante termina por concluir que el examen que nosotros hicimos de algunas osadas iniciativas de Rosas lo lleva a "sospechar que Rosas fue algo más que un producto de su contexto." No podemos dejar de señalar que compartimos solo parcialmente esta lectura y dejando de lado y a cargo de los lectores del libre la serie de elogiosos comentarios que incluye en su reseña, conviene centrarse en esta apreciación. Ante todo, porque nuestro modo de leer el contexto es radicalmente diferente sino directamente opuesto sobre todo porque si algo hemos tratado de conseguir -que lo hayamos logrado o no lo dirán los lectores- fue una lectura precisamente situada de las referencias documentales: esto es, evitando la postulación de explicaciones retrospectivas y tomadas como inevitables, como hizo Lynch muchas veces. El Rosas que intentamos mostrar es un Rosas situado que tuvo que tomar decisiones y adoptó un determinado curso de acción; no era el único posible pero tampoco las opciones eran infinitas o a libre elección. Rosas, como todos los actores, debía operar y actuar en un contexto y eso lo determinaba aunque el sentido de esa determinación no fuera unívoco. Por eso, nuestro énfasis en indagar hasta qué punto lograba comprender las tendencias en curso y los significados de las experiencias vividas apuntan a tratar de comprender algunas de las razones de 
la mayor peculiaridad de Rosas como líder político: las que puedan explicar su éxito para construirlo y reproducirlo.

Es bien probable, como dijimos antes, que nuestras lecturas de Rosas y del rosismo estén influidas por las experiencias políticas de los años recientes. Así, quizás nuestro crítico suponga que los márgenes de acción de un líder político son tan amplios que le permitan cambiar el mundo con su sola voluntad e inteligencia, establecer alianzas, cambiar legislaciones, fijar precios (de la carne y los alquileres, -o la luz y el gas!-), y con ello cambiar el mundo. Mientras que nuestra perspectiva ha intentado tener más en cuenta las condiciones que permiten que un líder político pueda modificar la realidad. Y esas condiciones tienen mucho que ver con su capacidad de comprender el contexto en el que se mueve y que limitan sus opciones, aunque no necesariamente sus objetivos. Si algo quisimos resaltar de la figura y el genio político de Rosas, -y ello claramente en oposición al grupo rivadaviano y quizás en parte al propio federalismo dorreguista- fue su capacidad para comprender los cambios que había traído la revolución, especialmente en el papel que habían ganado los sectores populares tanto rurales como urbanos, así como la división y debilidad de las elites. Y que, no difiriendo en última instancia, en el objetivo de restablecer el orden social y político con aquellos, si difirió sustancialmente en comprender cuáles debían ser los senderos que le permitirían cumplir con esos objetivos. Si esto no es dar relevancia a Rosas en tanto actor político, no entendemos qué sí lo sería. En esta cuestión, a nuestro entender -aunque bien puede ser que estemos equivocados- reside el llamado 'factor Rosas' que nos reclama Hora y que le otorgó al Restaurador un papel político determinante que ninguno antes pudo llevar a cabo, aún alguien como Dorrego, pero mucho menos un Rivadavia que suponía que podía alterar las reglas tradicionales de regulación de los conflictos, de distribución de los recursos, de administración del poder, etc. porque eso es lo que dictaba la lógica de la modernidad y el utilitarismo. En esto debemos decir que, y no es para apoyarnos en una autoridad intelectual incuestionable para nuestro crítico, coincidimos con las conclusiones a las que llegara Tulio Halperín Donghi, cuando señaló que para entender a Rosas "Lo que necesitamos entonces es un Rosas que sea de veras de su tiempo, y un Rosas que sea lo que en efecto fue: un político cuya originalidad no reside en la adhesión a ciertas ideas generales, sino en el invento de una solución conservadora para un país que ha atravesado una revolución y no querría ni podría suprimir la huella que ésta ha dejado en el cuerpo social tanto como en las convicciones colectivas" ${ }^{1}$

Ello nos lleva a considerar lo que de alguna manera Roy Hora nos reclama: que nuestro libro no termina de dar cuenta de eso que denomina "el factor Rosas". Es probable que así sea y en tal sentido lo que cabe esperar es que ${ }^{1}$ HALPERIN DONGHI, Tulio "Estudios recientes sobre el pensamiento político de Rosas", en
Ensayos de historiografía, Ed. El Cielo por Asalto, Buenos Aires, 1996, p. 142. 
quizás logremos contribuir involuntariamente a que un libro de ese tipo sea escrito. Desde nuestra perspectiva, dado el actual estado de los conocimientos y la disponibilidad documental, no era ese el libro que cabía emprender sin quedar atrapados en terrenos cenagosos que ya habían sido transitados. Y no lo era porque si algo caracterizó los recientes desarrollos historiográficos fue el escrutinio preciso y sistemático de un vastísimo conjunto documental que ofrecía nuevas posibilidades de indagar y de comprender no solo la trayectoria de Rosas sino las profundas mutaciones que vivía la sociedad rioplatense.

Y con eso no creemos haber engañado a nadie, lo proclamamos desde las primeras páginas de nuestro libro, y nos limitamos a repetir aquí algunas de esas consideraciones que nos parece responden a muchas de las objeciones planteadas por nuestro comentarista. Desde ya nos excusamos por el largo de la cita a nuestro propio libro (pp. 24 y 25):

"En este sentido, lo que nos proponemos no es estrictamente una biografía y menos aún una biografía convencional. Por cierto, la biografía ocupa un lugar peculiar en el campo historiográfico pues si bien es claro que se trata de una de las formas más antiguas del conocimiento histórico, ${ }^{2}$ también lo es que en los últimos años ha recuperado una notable vitalidad en la historiografía internacional siendo uno de los "retornos" que la caracterizan. ${ }^{3}$ Como se ha señalado, esta suerte de re-descubrimiento de la biografía no es ajeno a algunas utopías y está plagado de incertidumbres. ${ }^{4}$ Sin embargo, se ha reconocido que a pesar de sus dificultades el enfoque biográfico ofrece algunas posibilidades sugestivas en la medida que posibilita internarse en las opciones y estrategias de los sujetos, sus modos de movilizar los recursos disponibles o acrecentarlos y las maneras de moverse entre los quiebres y contradicciones de los sistemas normativos vigentes. ${ }^{5}$ Las opciones que afrontaron los sujetos biografiados no eran ineluctables pero tampoco infinitas y por tanto, solo puede haber dos o más biografías idénticas en un plano de muy alta abstracción, aun cuando se trate de sujetos que portaban una herencia análoga y se movieran en un contexto compartido. Su mundo relacional habría sido diferente y, sobre todo, porque lo habría sido su inserción en ese mundo relacional. Se trata, por tanto, de prestarle atención simultáneamente tanto a la especificidad con que cada individualidad se relacionaba con su entorno social como a los modos en que ese mundo social plasmaba esa individualidad en base a toda una gama de

2 MOMIGLIANO, Arnaldo Génesis y desarrollo de la biografía en Grecia, Fondo de Cultura Económica, México, 1986.

${ }^{3}$ LE GOFF, Jacques "Los retornos en la historiografía francesa actual", en Prohistoria, Año I, núm. 1, Rosario, 1997, pp. 35-44; BURDIEL, Isabel (ed.) "Dosier. Los retos de la biografía", en Ayer, núm. 93, Madrid, 2014, pp. 13-135.

4 BARRETO DE SOUZA, Adriana y LOPES, Fábio Henrique "Entrevista com Sabina Loriga: a biografia como problema", en História da historiografía, núm. 9, Ouro Preto, 2012, pp. 26-37.

${ }^{5}$ LEVI, Giovanni "Les usages de la biographie", en Annales. Économies, Sociétés, Civilisations, Vol. 44, núm. 6, París, 1989, pp. 1325-1336. 
relaciones. ${ }^{6}$ Pero no es el único desafío que se afronta y la cuestión es tan intrincada que no osaremos siquiera intentar resolverla pues ya ilustres y brillantes pensadores se han ocupado de ella. Al leerlos le queda claro al investigador los peligros que lo acechan de quedar aprisionado en lo que Pierre Bourdieu llamó la "ilusión biográfica". Advertía muy claramente el sociólogo francés que tratar la vida como una narración coherente de una secuencia significante y orientada de acontecimientos sería someterse a una ilusión retórica forjada por toda una tradición literaria. Por eso, sostenía que "Tratar de comprender una vida como una serie única y suficiente en sí de acontecimientos sucesivos sin más vínculo que la asociación a un 'sujeto' cuya constancia no es sin duda más que la de un nombre propio, es más o menos igual de absurdo que tratar de dar razón de un trayecto en el metro sin tener en cuenta la estructura de la red, es decir la matriz de las relaciones objetivas entre las diferentes estaciones."7

¿Hay algo más que pueda decirse sobre Rosas a comienzos del siglo XXI después de tanto que se ha escrito y discutido? Obviamente, los autores de este libro pensamos que sí, en la medida que seamos capaces de inscribir al sujeto en su mundo relacional y en sus mutaciones y reconstruir lo mejor que sea posible esa matriz de relaciones objetivas en la que estuvo inmerso. Rosas pudo tener aspiraciones, deseos, expectativas sobre su futuro pero su vida histórica en sociedad no puede ser entendida como el producto de un plan prefijado o de un devenir inevitable que solo se haría inteligible visto retrospectivamente.

Sin embargo, las advertencias no resuelven los problemas pues como en su momento señalara ese gran historiador que fuera Marc Bloch un hombre es menos hijo de su padre que de su época. Pero, ¿alcanza con conocer más y mejor una época para conocer a un hombre? Bloch no se engañaba y subrayaba que "los exploradores del pasado no son hombres del todo libres" y, por eso, una parte de la historia tiene inevitablemente "el aspecto, algo exangüe, de un mundo sin individuos". ${ }^{8}$

Rosas no fue siempre el mismo como no lo fue la sociedad en la que vivió ni lo fue ese fenómeno social y político que denominamos rosismo. No fue solo lo que quiso ser sino también lo que otros creyeron que era y quisieron que fuera. En ese sentido, quizás acertaba mucho su ilustre sobrino: para poder entender a Rosas y a su época “Es siempre interesante seguirle la pista á una

\footnotetext{
6 "Antropología y microhistoria: conversación con Giovanni Levi", en Manuscrits, núm. 11, Barcelona, 1993, pp. 15-28.

7 BOURDIEU, Pierre Razones prácticas. Sobre la teoría de la acción, Anagrama, Barcelona, 1997, pp. $74-83$.

8 BLOCH, Marc Apología para la historia o el oficio del historiador, Fondo de Cultura Económica, México, 2001, pp. 82-83.
} 
creencia popular, ya sea que perjudique o favorezca". 9 "Quizás podamos entender mejor a Rosas si seguimos las misteriosas pistas de esas creencias."

Fin de citación.

Desde nuestro punto de vista era preciso, primero, abandonar la pregunta infructuosamente repetida (¿quién fue Rosas?) y formularla de un modo históricamente más preciso y enriquecedor: ¿quién fue siendo Rosas, tanto para él como para el variopinto conjunto de actores sociales y políticos con los que interactuó? Una perspectiva de este tipo obligaba a tomar decisiones y una, de no menor significación en una biografía por "peculiar" que ella quiera ser, era manejarse con la cautela más puntillosa y cuidadosa que nos fuera posible sobre las dimensiones y facetas de su personalidad y de su vida íntima que no pudieran ser consistentemente documentadas. En este sentido, la insatisfacción de Roy Hora pareciera traer a la memoria aquello que había postulado Giambattista Vico en su Principi d'una scienza nuova intorno alla natura delle nazioni de 1744, pero no para hacer referencia al decurso de la historia sino para llamarnos la atención sobre los modos de acercamiento que pueden producirse desde la historiografía a un objeto que ha sido y sigue siendo motivo de reiteradas indagaciones. Comprender y explicar a Rosas a partir del "factor Rosas" ya había sido intentado y no solo una vez pero los resultados no parecen haber sido satisfactorios y sobre todo no contribuyeron demasiado al desarrollo de nuevos conocimientos.

Por eso, y en segundo término, se nos hizo necesario apuntar hacia una reformulación aún más integral del interrogante e intentar aproximar algunas respuestas a una enunciación más inquietante pero más decisiva aunque elusiva: ¿qué fue siendo Rosas? Roy Hora advierte con claridad algunos de los límites de nuestra contribución y uno en especial: nos dice que "se describen una serie de ámbitos de actividad y una serie de acciones singulares, pero no tenemos un argumento sustantivo que enhebre todo esto en una historia política del Rosas líder urbano que una narración y explicación" y, por lo tanto, que "sigue siendo insuficiente para entender cómo Rosas construye su poder en la ciudad, y qué es lo que hace que sea visto como distinto a otras ofertas políticas." Él mismo ofrece una explicación, que solo en parte nos disculpa: más que una carencia propia de nuestro libro lo que se revela es "una limitación más general de nuestra historiografía" sobre la historia política "urbana". Pero la observación solo podemos compartirla parcialmente: si bien es evidente que se hace perentorio avanzar hacia la producción de un conocimiento de la historia de la ciudad tan sistemática y exhaustiva como la que se ha realizado en el ámbito rural también lo es que difícilmente ello pueda producirse efectivamente si se sigue pensando e imaginando esta sociedad (y su economía, su política o

${ }^{9}$ MANSILLA, Lucio V. Rozas.... cit, p. 124. 
su cultura) a partir de una visión dicotómica entre lo urbano y lo rural y, sobre todo si "lo urbano" se sigue concibiendo tan solo como "la ciudad".

Pero, así como nuestro crítico ha identificado con claridad una zona menos consistente del conocimiento historiográfico en que nos apoyamos no ha enfatizado otras que nosotros mismos indicamos y que tienen particular relevancia para responder con mayor consistencia al interrogante de ¿qué fue Rosas? Por lo pronto, porque hubiera hecho falta la escritura de un volumen de extensión probablemente equivalente para dar cuenta del Rosas que se fue construyendo y transformando en cada uno de los territorios que conformaron la Confederación Argentina y más allá de sus límites formales. Pero, como alegato a nuestro favor, cabría decir que el conocimiento al respecto es todavía muy irregular aunque es muy probable que habríamos podido avanzar mucho más al respecto de lo que lo hicimos. Se trata de una deuda pendiente, al igual que el estudio mucho más exhaustivo de la última década de Rosas en el poder. Este momento, de la llamada "pax rosista" ha sido muy mal y poco estudiado por los historiadores hasta ahora y ello se debe seguramente a la propia consolidación del régimen que convirtió en rutinarias las prácticas gubernativas y escasamente informativas a las fuentes elaboradas por los agentes de gobierno, en que basamos una gran parte de nuestras indagaciones. Sin embargo hay formas de abordar esta etapa, que además de mostrarnos y explicarnos el éxito de Rosas, nos pueden ayudar a entender un final que podría parecer a primera vista no demasiado lógico según las trayectorias conocidas. Por el momento, parece bastante claro que durante la década final del rosismo sus relaciones con el universo plebeyo, que tan decisivo había sido para su llegada al poder en 1829 o para su capacidad de superación de la fenomenal crisis de 1839, debió haberse modificado sustancialmente para 1852. Y si bien disponemos de conjeturas plausibles para analizar ese recorrido parece bastante evidente que aun la cuestión amerita una indagación en profundidad que ofrezca una explicación mucho más consistente y satisfactoria.

Pero también porque si algo nos dejó en claro esta experiencia de escritura es que hay todavía una enorme y significativa cuestión que aun debe ser examinada y develada en profundidad: ¿Cómo procesaron, elaboraron y afrontaron la derrota de Rosas y del rosismo los heterogéneos grupos subalternos que le habían servido de consistente y decisivo apoyo? ¿Cuándo sacaremos a la luz los pliegues y las mutaciones de las memorias populares de Rosas? Cuando ello suceda seguramente habrá que escribir otra biografía peculiar. 